JURNAL KEBIDANAN

Vol 6, No 4, Oktober 2020 : 493-496

\title{
PEMBERIAN AIR DAUN PANDAN TERHADAP PENURUNAN KADAR GULA DARAH PADA PASIEN DIABETES
}

\author{
Nurhaida Br Kaban¹, Pratiwi Syah Putri² \\ 1,2Kebidanan Stikes Flora Medan \\ 1 email : nurhaidakaban@gmail.com \\ 2email pratiwi.2188@gmail.com
}

\begin{abstract}
Background : Diabetes Mellitus is a group of metabolic diseases characterized by an increase in glucose levels in the blood quickly. The number of patients with Diabetes Mellitus Treatment is quite expensive, so many sufferers try to control their blood glucose levels by traditional medicine. One of the plants used as traditional medicine is fragrant pandanus. patients.

Purpose : To analyze the effect of giving pandan leaf water to the decrease in blood sugar levels in Diabetes

Methods : This type of research is a pre-experimental study using the design of the one group pretest posttest. The study was located in the Sundari hospital in Medan city. The study population was all patients of Diabetes Mellitus who were recorded in the medical records of Sundari hospital period of January 2018-July 2018, totaling 126 people. The sample size is 20 people. Data analysis using paired-sample $t$ test with data normally distributed at significance level $\alpha=0.05$.

Results: The results of the study were that there were differences in blood sugar levels in the pretest and posttest drinking pandan leaf water, where the average blood sugar level of the pretest respondents was $225.25 \pm$ 17.423; posttest $H+1$ was $212.95 \pm 15,883$; posttest $H+3$ of $197.65 \pm 12.381$; and posttest $H+7$ of $181.25 \pm$ 11.584 .

Conclusion: The conclusion is that there is an effect of giving boiled water of pandan leaves to a decrease in blood sugar levels in diabetic patients at Sundari hospital in Medan city.

Suggestion The boiled water of fragrant pandan leaves can be an alternative to lower blood sugar levels in diabetes patients
\end{abstract}

Keywords : Diabetes mellitus, pandan leaf, blood sugar levels

\section{ABSTRAK}

Latar Belakang : Diabetes Mellitus merupakan kelompok penyakit metabolisme yang ditandai adanya peningkatan kadar glukosa dalam darah secara cepat. Jumlah penderita Pengobatan Diabetes Mellitus membutuhkan biaya yang cukup mahal sehingga banyak penderita yang berusaha mengendalikan kadar glukosa darahnya dengan cara pengobatan tradisional. Salah satu tanaman yang digunakan sebagai obat tradisional adalah pandan wangi.

Tujuan : Untuk menganalisis pengaruh pemberian air daun pandan terhadap penurunan kadar gula darah pada pasien Diabetes di Rumah Sakit Sundari Kec.Sunggal Kota Medan.

Jenis penelitian ini adalah penelitian pre experiment dengan menggunakan desain one group pretest posttest. Penelitian berlokasi di Rumah Sakit Sundari Kec.Sunggal Kota Medan. Populasi penelitian yaitu seluruh pasien Diabetes Mellitus yang tercatat di rekam medis Rumah Sakit Sundari Kec.Sunggal Kota Medan periode Januari 2018-Juli 2018 yaitu sebanyak 126 orang. Besar sampel sebanyak 20 orang. Analisis data menggunakan paired-sample $t$ test dengan data berdistribusi normal pada tingkat kemaknaan $\alpha=0,05$

Hasil : Hasil penelitian adalah terdapat perbedaan kadar gula darah pretest dan posttest meminum air daun pandan dimana rata-rata kadar gula darah responden pretest sebesar 225,25 $\pm 17,423$; posttest $\mathrm{H}+1$ sebesar

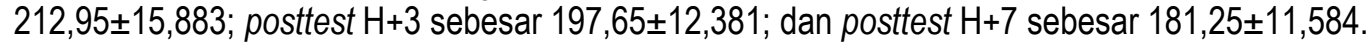

Kesimpulan : Ada pengaruh pemberian rebusan air daun pandan terhadap penurunan kadar gula darah pada pasien Diabetes di Rumah Sakit Sundari Kota Medan.

Saran: Rebusan air daun pandan wangi dapat menjadi salah satu alternatif untuk menurunkan kadar gula darah pada pasien diabetes

Kata Kunci : Diabetes ellitus, saun pandan, kadar gula darah 


\section{PENDAHULUAN}

Hiperglikemia adalah suatu kondisi medik berupa peningkatan kadar glukosa dalam darah melebihi batas normal (Soelistijo et al., 2015). Diabetes Mellitus merupakan kelompok penyakit metabolisme yang ditandai dengan adanya hiperglikemia Ta, S. (2014).

Diabetes Mellitus semakin banyak diderita penduduk dunia seiring bertambahnya usia harapan hidup. Badan kesehatan dunia memprediksi ada peningkatan jumlah penyandang diabetes yang menjadi ancaman global (Soelistijo et al., 2015). Diperkirakan, prevalensinya akan meningkat dua kali pada tahun 2030 sebanyak 366 juta atau 4,4\% dari penduduk dunia (Cho et al., 2018). Diabetes Mellitus telah membunuh 38 juta orang di dunia tiap tahunnya (WHO, 2016). Indonesia menempati urutan ke-4 dengan jumlah penderita 8,4 juta terbesar di dunia setelah India, Cina, dan Amerika Serikat (WHO, 2016). Diabetes merupakan satu dari empat PTM utama. Kelompok usia 55-64 tahun adalah kelompok terbanyak yang terserang penyakit ini (Kemenkes, 2013). Hal ini akan menjadi beban yang sangat berat untuk ditangani (Soelistijo et al., 2015).

Diabetes Mellitus dikenal sebagai "silent killer. Timbulnya penyakit ini berasal dari berbagai faktor (Fajar, 2016). Komplikasi yang terjadi berisiko mortalitas dan morbiditas (Cho et al., 2018). Pengobatan diabetes membutuhkan biaya yang cukup mahal sehingga banyak penderita berusaha mengendalikan kadar glukosa darahnya dengan pengobatan tradisional menggunakan tanaman herbal karena relatif lebih aman, harga lebih murah dan efek samping minimal dibandingkan obat sintetik (WHO, 2012; Prameswari \& Widjanarko, 2014; Berawi, Perkasa, \& Rachmanisa, 2014).

Indonesia merupakan negara tropis yang kaya akan kekayaan alamnya. Diperkirakan Indonesia memiliki lebih dari 25.000 macam tanaman yang diindikasikan sebagai obat tradisional untuk mencegah beberapa penyakit. Salah satunya pandan wangi atau Pandanus amarylifolius Roxb. Pandan wangi adalah tanaman monokotil dari family Pandanaceae yang daunnya beraroma wangi yang khas (Prameswari \& Widjanarko, 2014).

Uji preklinik daun pandan wangi telah dilakukan oleh Prameswari \& Widjanarko (2014) bahwa empat senyawa aktif yang terkandung dalam air daun pandan wangi yaitu tannin, alkaloid, flavonoid dan polifenol memiliki aktivitas hipoglikemik. Dosis ekstrak air daun pandan 600 $\mathrm{mg} / \mathrm{kg}$ bb diduga lebih baik dalam menurunkan kadar glukosa darah dan memperbaiki jaringan pankreas. Hasil penelitian tersebut didukung dengan penelitian (Nastiandari, 2016) bahwa air rebusan daun pandan wangi dapat menurunkan kadar glukosa darah dengan dosis pemakaian $200 \mathrm{~mL}$ untuk sekali minum. Penelitian Sukandar dkk (2009) dalam (Prameswari \& Widjanarko, 2014), ekstrak etil asetat daun pandan wangi mengandung senyawa terpenoid dan steroid yang berpotensi sebagai antidiabetes secara in vitro dengan daya hambat sebesar $0,79 \%$ pada konsentrasi 3,12 ppm.

Perilaku pencarian pengobatan sebagian masyarakat masih menggunakan tanaman ataupun bahan dapur. Mereka meracik ramuan sendiri menurut pengalamannya, tanpa menggunakan dosis yang tepat. Hasil wawancara 5 pasien diperoleh informasi bahwa mereka belum mengetahui daun pandan dapat digunakan dalam mengontrol atau menurunkan kadar glukosa darah. Mereka mengkonsumsi belimbing, buncis, sirih merah, dan mengkudu untuk menurunkan kadar glukosa darahnya., bahkan ada yang mengatasinya dengan menghindari makanan manis dan mengurangi porsi makan.

Berdasarkan uraian latar belakang diatas, maka peneliti merasa tertarik untuk melakukan penelitian tentang "Pengaruh Pemberian Air Daun Pandan terhadap Penurunan Kadar Glukosa Darah Pada Penderita Diabetes".

\section{METODOLOGI PENELITIAN}

Jenis penelitian ini adalah pre experiment dengan desain one group pretest posttest yang bertujuan untuk mengetahui pengaruh pemberian air daun pandan terhadap penurunan kadar gula darah. Penelitian ini dilakukan di RS Sundari Kota Medan sejak Januari 2020 sampai dengan April 2020. Populasi dalam penelitian ini adalah seluruh pasien diabetes mellitus yang tercatat di rekam medis periode Januari 2019-Desember 2019 yaitu sebanyak 126 orang. Penentuan besar sampel menggunakan rumus Roscoe (1982) sebanyak 20 orang. Teknik pengambilan sampel adalah simple random sampling dengan sistem undian.

Metode pengumpulan data dengan data primer dan sekunder. Data primer diperoleh dari hasil wawancara langsung kepada responden berpanduan kuesioner dan pengukuran kadar glukosa darah responden menggunakan accu check dan hasilnya ditulis pada lembar observasi penelitian. Sedangkan data sekunder didapatkan dari rekam medis RS Sundari Kota Medan tentang jumlah pasien diabetes mellitus periode Januari 2019-Desember 2019, selain itu melalui buku, jurnal maupun artikel yang terkait dengan topik penelitian ini.

Alat penelitian yang digunakan antara lain glukometer, gelas ukur, kuesioner dan lembar 
observasi. Seluruh data yang telah terkumpul, kemudian dilakukan analisis data menggunakan uji paired -sample t test untuk melihat perubahan kadar gula darah sebelum dan sesudah perlakuan. Kesimpulan dari uji ini diambil dengan ketentuan bila $p$ value $<0,05$ berarti hasil perhitungan statistik bermakna (signifikan), dan bila nilai $p$ value $>0,05$ berarti hasil perhitungan statistik tidak bermakna.

HASIL

Perbedaan kadar gula darah responden pretest dengan posttest, selengkapnya dapat dilihat pada tabel 1 sebagai berikut:

Tabel 1

Perbedaan Kadar Gula Darah Pretest dengan Posttest

\begin{tabular}{cccc}
\hline Uji & Kadar Gula Darah & $\overline{\mathbf{X} \pm \text { SD }}$ & $\boldsymbol{p}$ \\
\hline Paired 1 & Pretest & $225,25 \pm 17,423$ & 0,000 \\
& Posttest $\mathrm{H}+1$ & $212,95 \pm 15,883$ & \\
Paired 2 & Posttest $\mathrm{H}+1$ & $212,95 \pm 15,883$ & 0,000 \\
& Posttest $\mathrm{H}+3$ & $197,65 \pm 12,381$ & \\
Paired 3 & Posttest $\mathrm{H}+3$ & $197,65 \pm 12,381$ & 0,000 \\
& Posttest $\mathrm{H}+7$ & $181,25 \pm 11,584$ & 0,000 \\
Paired 4 & Pretest & $225,25 \pm 17,423$ & \\
& Posttest H+7 & $181,25 \pm 11,584$ & \\
\hline
\end{tabular}

Berdasarkan hasil penelitian didapatkan ratarata kadar gula darah responden pretest sebesar $225,25 \pm 17,423$ dan posttest $\mathrm{H}+1$ sebesar $212,95 \pm 15,883$; kadar gula darah responden posttest $\mathrm{H}+1$ sebesar $212,95 \pm 15,883$ dan posttest $H+3$ sebesar $197,65 \pm 12,381$; kadar gula darah responden posttest $\mathrm{H}+3$ sebesar $197,65 \pm 12,381$ dan posttest $\mathrm{H}+7$ sebesar $181,25 \pm 11,584$; serta kadar gula darah responden pretest sebesar $225,25 \pm 17,423$ dan posttest $\mathrm{H}+7$ sebesar $181,25 \pm 11,584$. Dari hasil uji diperoleh nilai $p$ sebesar 0,000 artinya terdapat perbedaan kadar gula darah pretest dan posttest meminum air daun pandan. Maka demikian dapat dinyatakan ada pengaruh pemberian rebusan air daun pandan terhadap penurunan kadar gula darah pada pasien diabetes di Rumah Sakit Sundari Kec. Sunggal Kota Medan.

\section{PEMBAHASAN}

Hasil penelitian terhadap penderita diabetes mellitus sebelum diberikan terapi rebusan air daun pandan wangi (Pandanus amarylifolius Roxb) di Rumah Sakit Sundari Kec. Sunggal Kota Medan didapatkan rata-rata kadar glukosa darah sewaktu sebesar $225,25 \mathrm{mg} / \mathrm{dl}$. Setelah diberikan rebusan air daun pandan wangi, rata-rata kadar glukosa darah sewaktu $\mathrm{H}+1$ sebesar $212,95 \mathrm{mg} / \mathrm{dl} ; \mathrm{H}+3$ sebesar $197,65 \mathrm{mg} / \mathrm{dl}$ dan H+7 sebesar 181,25 mg/dl. Dari hasil penelitian ini terlihat ada perbedaan kadar gula darah pretest dan posttest meminum air daun pandan $(p=0,000<0,05)$. Maka demikian dapat dinyatakan bahwa ada pengaruh pemberian rebusan air daun pandan terhadap penurunan kadar gula darah pada pasien Diabetes di Rumah Sakit Sundari Kec.Sunggal Kota Medan.

Hasil penelitian ini tidak sejalan dengan penelitian yang dilakukan oleh (Prameswari \& Widjanarko, 2014) menyatakan bahwa berdasarkan uji in vivo didapatkan terapi diabetes dengan obat metformin lebih efektif menurunkan kadar glukosa darah dibandingkan ekstrak air daun pandan wangi, namun tidak lebih baik dalam memperbaiki kerusakan jaringan pankreas yang diakibatkan oleh senyawa diabetogenik aloksan.

Penurunan kadar glukosa darah dengan terapi air daun pandan wangi dapat disebabkan adanya kandungan senyawa bioaktif yaitu tanin, alkaloid, flavonoid, dan polifenol yang dapat mencegah terjadinya oksidasi sel $\beta$ pankreas sehingga kerusakan dapat diminimalkan. Menurut penelitian yang dilakukan oleh Agustiningsih dan Achmad pada tahun 2010 ditemukan kandungan flavonoid dalam daun pandan yaitu sebesar 4,6 $\mathrm{mg} / \mathrm{dl}$ ekstrak. Kandungan tannin yang terkandung dalam daun pandan akan bekerja sebagai penenang, sehingga tidak memberikan efek sebagai astringen. Selain itu, kandungan kalsium tidak ditemukan di dalam daun pandan, sehingga tidak memberikan efek hipoglikemik bagi yang mengkonsumsi.

Sesuai dengan teori yang dikemukan oleh Nurrahmani (2012) dan Wijoyo (2010) menyatakan bahwa ada beberapa faktor yang dapat memengaruhi terhadap kadar glukosa darah diantaranya kurang sensitifnya jaringan tubuh terhadap insulin karena jumlah atau aktivitas reseptor insulin berkurang pada sel, pola makan 
yang berlebihan menyebabkan kadar glukosa dalam darah meningkat karena keterbatasan sel $\beta$ pancreas untuk mensekresi insulin, obesitas mengakibatkan lemak yang berlebihan hal ini akan menyebabkan resistensi terhadap insulin, faktor genetik dapat menyebabakan diabetes mellitus karena diwarisinya gen penyebab diabetes mellitus, bahan-bahan kimia dan obat-obatan tertentu dapat menyebabkan radang pankreas sehingga pankreas tidak berfungsi secara optimal.

Faktor selanjutnya yang dapat memberikan pengaruh terhadap kadar glukosa darah adalah stress. Stres dapat menyebabkan tubuh menghasilkan hormon-hormon racun. Kondisi stress yang berlangsung secara terus-menerus akan menyebabkan terjadi kandungan racun yang melimpah di dalam tubuh. Inilah yang kemudian akan mengacaukan seluruh metabolisme tubuh. Sensitivitas insulin pun menjadi terganggu dan menyebabkan terjadinya diabetes mellitus (Nurrahmani, 2012).

Selanjutnya, pola makan melebihi jumlah kadar kalori yang dibutuhkan tubuh dapat memacu timbulnya hiperglikemia dan tidak diimbangi oleh sekresi insulin dalam jumlah memadai menyebabkan kadar glukosa semakin meningkat. Berdasarkan hasil penelitian yang dilakukan oleh The Nurses' Health Study II terhadap 51.603 wanita usia 22-44, ditemukan peningkatan konsumsi makanan manis dan minuman bersoda berisiko diabetes mellitus. Kenaikan risiko itu terjadi dikarenakan kandungan pemanis yang terdapat dalam makanan atau minuman bersoda.tersebut. Selain itu juga, asupan kalori cair tidak membuat kita kenyang sehingga akan terdorong untuk minum atau makan yang lebih banyak (Nurrahmani, 2012).

Menurut Waid (2011), rebusan air daun pandan wangi (Pandanus amarylifolius Roxb) merupakan tumbuhan obat yang bermanfaat sebagai penormal fungsi kelenjar pankreas dengan efek farmakologis memperlancar sistem sirkulasi darah dalam membantu menormalkan fungsi pankreas dalam mengatasi diabetes mellitus.

\section{KESIMPULAN}

Ada pengaruh pemberian rebusan air daun pandan wangi (Pandanus amarylifolius Roxb) terhadap penurunan kadar gula darah pada pasien diabetes di Rumah Sakit Sundari Kec. Sunggal Kota Medan.

\section{SARAN}

Rebusan air daun pandan wangi dapat menjadi salah satu alternatif untuk menurunkan kadar gula darah pada pasien diabetes

\section{DAFTAR PUSTAKA}

Berawi, KN., Perkasa, N.I.B., \& Rachmanisa, S. (2014). The effects of the ethanol extract banana peel (Musa paradisiacal) on glucose levels in rat strain (Sprague dawley) induced alloxan. Medical Journal of Lampung University, 3(1), 11-114.

Cho, N., Shaw, J. E., Karuranga, S., Huang, Y., da Rocha Fernandes, J. D., Ohlrogge, A. W., \& Malanda, B. (2018). IDF Diabetes Atlas: Global estimates of diabetes prevalence for 2017 and projections for 2045. Diabetes research and clinical practice, 138, 271-281.

Kemenkes, R. I. (2013). Laporan riset kesehatan dasar 2013. Jakarta: Badan Penelitian dan Pengembangan Kesehatan Kementerian Kesehatan Republik Indonesia.

PUTRI FAJAR, R. A. I. S. H. A. (2016). MENU DIET PASIEN PENDERITA DIABETES MELLITUS DI RS IMMANUEL BANDUNG.

PUTRIANI, Y. E. PENGARUH AIR REBUSAN DAUN PANDAN WANGI (Pandanus amaryllifolius Roxb.) TERHADAP PENURUNAN TEKANAN DARAH TINGGI PADA TIKUS PUTIH (Rattus norvegicus L.) DAN PEMANFAATANNYA SEBAGAI KARYA ILMIAH POPULAR.

Nurrahmani, U. (2012). Stop! Kolesterol Tinggi. Familia. Yogyakarta.

Prameswari, O.M., \& Widjanarko, S.B. (2014), Uji efek ekstrak air daun pandan wangi terhadap penurunan kadar glukosa darah dan histopatologi tikus diabetes mellitus. Jurnal Pangan dan Agroindustri, 2(2), 16-27.

Soelistijo, et al. (2015). Kondensus pengelolaan dan pencegahan diabetes mellitus tipe $2 \mathrm{di}$ Indonesia. Jakata : PB Perkeni.

Ta, S. (2014). Diagnosis and classification of diabetes mellitus. Diabetes care, 37(1), 8190.

Waid, A. (2011). Dahsyatnya khasiat daun-daun obat di sekitar pekaranganmu. Yogyakarta: Laksana.

WHO. (2012). WHO traditional medicine strategy. Geneva : WHO

Wijoyo, P.M. (2012). Cara tuntas menyembuhkan diabetes dengan herbal. Jakarta: Pustaka Argo Indonesia.

Wildan, A. (2010). OPTIMASI CAIRAN PENYARI PADA PEMBUATAN EKSTRAK DAUN PANDAN WANGI (Pandanus amaryllifous Roxb) SECARA MASERASI TERHADAP KADAR FENOLIK DAN FLAVONOID TOTAL. MAJALAH ILMIAH MOMENTUM, 6(2). 